\title{
Comparative Study of the Coprecipitation Methods for the Preparation of Layered Double Hydroxides
}

\author{
Eduardo L. Crepaldi, Paulo C. Pavan and João B. Valim* \\ Departamento de Química, Faculdade de Filosofia, Ciências e Letras de Ribeirão Preto, \\ Universidade de São Paulo, Av. dos Bandeirantes, 3900, 14.040-901, Ribeirão Preto - SP, Brazil
}

\begin{abstract}
A coprecipitação é o método mais frequentemente utilizado para preparar Hidróxidos Duplos Lamelares (HDLs). Duas variações deste método podem ser utilizadas, dependendo das condições adotadas quanto ao controle de $\mathrm{pH}$ durante a etapa de precipitação. No primeiro caso o pH não é controlado e a síntese é conduzida em pH variável, ao passo que no segundo caso o pH é mantido constante durante a precipitação. Apesar de cada grupo de pesquisa ter suas preferências, nenhum estudo sistemático e comparativo destas duas variações do método está disponível na literatura. Desta forma, o objetivo deste estudo foi comparar as propriedades de HDLs preparados através das duas variações possíveis do método de coprecipitação. Os resultados demonstraram que, embora seja mais simples a síntese realizada sem controle de $\mathrm{pH}$, materiais com propriedades mais interessantes do ponto de vista tecnológico foram obtidos pelo método que utiliza $\mathrm{pH}$ constante. Materiais com maior cristalinidade, partículas menores, maior área superficial e maior diâmetro médio de poros foram obtidos pelo método de coprecipitação em $\mathrm{pH}$ constante.
\end{abstract}

Coprecipitation is the method most frequently applied to prepare Layered Double Hydroxides (LDHs). Two variations of this method can be used, depending on the $\mathrm{pH}$ control conditions during the precipitation step. In one case the $\mathrm{pH}$ values are allowed to vary while in the other they are kept constant throughout coprecipitation. Although research groups have their preferences, no systematic comparison of the two variations of the coprecipitation method is available in the literature. On this basis, the objective of the present study was to compare the properties of LDHs prepared using the two forms of $\mathrm{pH}$ control in the coprecipitation method. The results showed that even though coprecipitation is easier to perform under conditions of variable $\mathrm{pH}$ values, materials with more interesting properties, from the point of view of technological applications, are obtained at constant $\mathrm{pH}$. Higher crystallinity, smaller particle size, higher specific surface area and higher average pore diameter were found for materials obtained by coprecipitation at constant $\mathrm{pH}$, when compared to the materials obtained at variable $\mathrm{pH}$.

Keywords: layered double hydroxides, coprecipitation, intercalation, hydrotalcite.

\section{Introduction}

Layered double hydroxides (LDHs) have received considerable attention due to their properties and potential applications as catalysts ${ }^{1-4}$, catalyst precursors or catalyst support ${ }^{5-6}$, adsorbents 7 , and anion exchangers ${ }^{8-10}$. LDHs consist of stacks of positively charged metal hydroxide layers which require the presence of interlayer anions to maintain overall charge neutrality. The most important class of LDHs can be represented by the general formula $\left[\mathrm{M}^{2+}{ }_{1-\mathrm{x}}\right.$ $\left.\mathrm{M}^{3+}{ }_{\mathrm{x}}(\mathrm{OH})_{2}\right]^{\mathrm{x}+} \mathrm{A}^{\mathrm{m}-}{ }_{\mathrm{x} / \mathrm{m}} \cdot \mathrm{nH}_{2} \mathrm{O}$, where $\mathrm{M}^{2+}$ is a bivalent cation, $\mathrm{M}^{3+}$ is a trivalent cation and $\mathrm{A}$ an interlamellar anion with charge $\mathrm{m}-$. The layers have a brucite-like structure

e-mail: jobvalim@usp.br
$\left[\mathrm{Mg}(\mathrm{OH})_{2}\right]$ in which the isomorphic substitution of some divalent cations by trivalent ones gives rise to the positive charge. In order to keep the electroneutrality, the interlamellar domain must be occupied by an adequate number of anions which are generally hydrated. A great variety of this kind of compounds can be obtained by varying the di- and trivalent cations, their proportions and the interlamellar anions.

The direct synthesis of such materials can be performed by various methods such as coprecipitation (or salt-base method) ${ }^{11,12}$, salt-oxide method ${ }^{10,13}$ and hydrothermal synthesis 11 . Other methods of direct synthesis are found in the literature, such as electrochemical synthesis 14,15 and sol-gel synthesis 16 , but these methods have been barely studied up to now. Among the direct methods, the most utilized one is coprecipitation, which can be carried out under constant or 
variable $\mathrm{pH}$, depending on the applied conditions. Even though many reports are available in the literature on $\mathrm{LDH}$ preparations using this method, a comparative systematic study on the effect of the different conditions involved in this method has not been carried out.

In the present study LDHs were prepared by the coprecipitation method using constant and variable $\mathrm{pH}$ values. The cation pairs used in the preparations were $\mathrm{Mg}(\mathrm{II})-\mathrm{Al}(\mathrm{III})$ and $\mathrm{Zn}$ (II)-Cr(III), some of the most frequently used combinations. In order to prepare representative materials, two kinds of anions were used, a carboxylate (terephthalate, represented by TA) and a sulfated surfactant (dodecylsulfate, represented by DS). The aim of this investigation was to study and compare properties such as crystallinity, phase purity, thermal stability, particle size distribution, average particle diameter, and textural properties of the prepared materials using the two variations of the coprecipitation methods.

\section{Experimental}

All cations salts used, $\mathrm{Mg}\left(\mathrm{NO}_{3}\right)_{2} \cdot 6 \mathrm{H}_{2} \mathrm{O}, \mathrm{Al}\left(\mathrm{NO}_{3}\right)_{3}$ $.9 \mathrm{H}_{2} \mathrm{O}, \mathrm{Zn}\left(\mathrm{NO}_{3}\right)_{2} \cdot 6 \mathrm{H}_{2} \mathrm{O}$ and $\mathrm{Cr}\left(\mathrm{NO}_{3}\right)_{3} \cdot 9 \mathrm{H}_{2} \mathrm{O}$ were of analytical grade and were purchased from Merck. Sodium dodecylsulfate was also of the highest available purity (Merck), and was further purified by the Soxhlet extraction with hexane in order to extract residual 1-dodecanol. The elimination of 1-dodecanol was confirmed by measurements of the CMC of the surfactant, using a conductiometric method 17 . Sodium terephthalate was prepared by addition of a $\mathrm{NaOH}$ (Merck >98\%) solution to a suspension of terephthalic acid $(99.9 \%)$ which was obtained from Rhodiaco Indústrias Químicas Ltda.

The synthesis conducted at constant $\mathrm{pH}$ was carried out by the addition of the cation solution $\left(\mathrm{M}^{2+}=2.5 \times\right.$ $10^{-2} \mathrm{~mol}$ and $\mathrm{M}^{3+}=8.3 \times 10^{-3} \mathrm{~mol}$ both dissolved in $17 \mathrm{~cm}^{3}$ of water) to a solution of the anion to be intercalated (SDS $=1.66 \times 10^{-2} \mathrm{~mol}$ and terephthalate $=8.3 \times 10^{-3} \mathrm{~mol}$ each one dissolved in $70 \mathrm{~cm}^{3}$ of water). A $2 \mathrm{~mol} \mathrm{dm}^{-3} \mathrm{NaOH}$ solution was concomitantly added in order to keep the $\mathrm{pH}$ constant. Different $\mathrm{pH}$ values were used to prepare the LDHs, i.e., $7.0 \pm 0.2$ for the $\mathrm{Zn}-\mathrm{Cr}-\mathrm{LDHs}$ and $8.5 \pm 0.2$ for the Mg-Al-LDHs.

In the preparation at variable $\mathrm{pH}$ values, the cation solution with an MII:MIII ratio of 3:1 was added (identical to the one used in the constant $\mathrm{pH}$ method) to an alkaline solution $(0.133 \mathrm{~mol}$ of $\mathrm{NaOH})$ of the anion in $70 \mathrm{~cm}^{3}$ of water. The amounts of cations and anions were identical to those used in the method of coprecipitation at constant $\mathrm{pH}$.
In both cases, the materials obtained were water washed by centrifugation and dried under vacuum. Part of the materials obtained was separated before drying and submitted to hydrothermal treatment $\left(100^{\circ} \mathrm{C}\right.$ for $18 \mathrm{~h}$ at atmospheric pressure), after which it was centrifuged again and vacuum dried.

The materials were characterized using powder X-ray diffraction (PXRD), thermogravimetric and differential thermal analysis (TG/DTA), light scattering, $\mathrm{N}_{2}$-BET and scanning electron microscopy (SEM).

A Siemens D5005 X-ray diffractometer with a $\mathrm{Cu} \mathrm{K}$ radiation $(\lambda=1.5406 \AA)$ and a graphite crystal as monochromator, was used to obtain the PXRD patterns ranging from 2 to $70^{\circ} 2 \theta$, using a step of $0.020^{\circ} \mathrm{s}^{-1}$. TG/DTA analyses were performed using an SDT 2960 Simultaneous DTA-TGA coupled to a Thermal Analyst 2100, both from TA Instruments, in dry synthetic air at a heating rate of $10^{\circ} \mathrm{C} \mathrm{min}^{-1}$.

Size distribution and average diameter of the particles in suspension were determined by light scattering. A Zetasizer 4 coupled to a SX/16 microcomputer from Malvern was used to obtain the measurements. Specific surface area and average pore diameter were determined by the $\mathrm{N}_{2}$-BET isotherm technique using a Micromeritics ASAP 2010 apparatus. Before the beginning of each measurement, the samples were outgassed at $40^{\circ} \mathrm{C}$ (higher temperatures were avoided because of the thermal decomposition, see Figure 2) for $1 \mathrm{~h}$.

The SEM images were taken with a Zeiss DSM960 Digital Scanning Microscope. The powder solids were deposited on the sample-holder by dip-coating the supports in the suspension of each material and submitted to gold sputtering with a Sputter Coater Balzers SCD 050.

\section{Results and Discussion}

\section{Prepared materials}

By varying the cation combination, interlamellar anion and $\mathrm{pH}$ control during coprecipitation, with or without submission to hydrothermal treatment a total amount of 16 samples was obtained. The prepared materials are organized in Table 1 according to the denomination adopted.

Table 1. Description of the prepared materials.

\begin{tabular}{llll}
\hline cMgAlTA & cMgAlDS & cZnCrTA & cZnCrDS \\
\hline cMgAlTA-ht & cMgAlDS-ht & cZnCrTA-ht & cZnCrDS-ht \\
\hline vMgAlTA & vMgAlDS & vZnCrTA & vZnCrDS \\
\hline vMgAlTA-ht & vMgAlDS-ht & vZnCrTA-ht & vZnCrDS-ht
\end{tabular}

c-denotes constant $\mathrm{pH}$; $\mathrm{v}$ denotes variable $\mathrm{pH}$ and ht-means submission to hydrothermal treatment. 


\section{Powder X-ray diffraction patterns}

Figure 1 shows the PXRD patterns for the materials prepared under different conditions of $\mathrm{pH}$ during precipitation and hydrothermal treatment. The basal spacing of $\sim 14$ and $\sim 27 \AA$ was found for the TA- and DS-containing LDHs, respectively, depending on the system and on the submission to hydrothermal treatment. The Miller indexes indicated were based on literature data 18 , and the values of basal spacing were then calculated by the Bragg equation, using the average $1 / 3\left(d_{003}+d_{006}+d_{009}\right)$. The basal spacings obtained agree with those reported in the literature for these anions ${ }^{19}$.
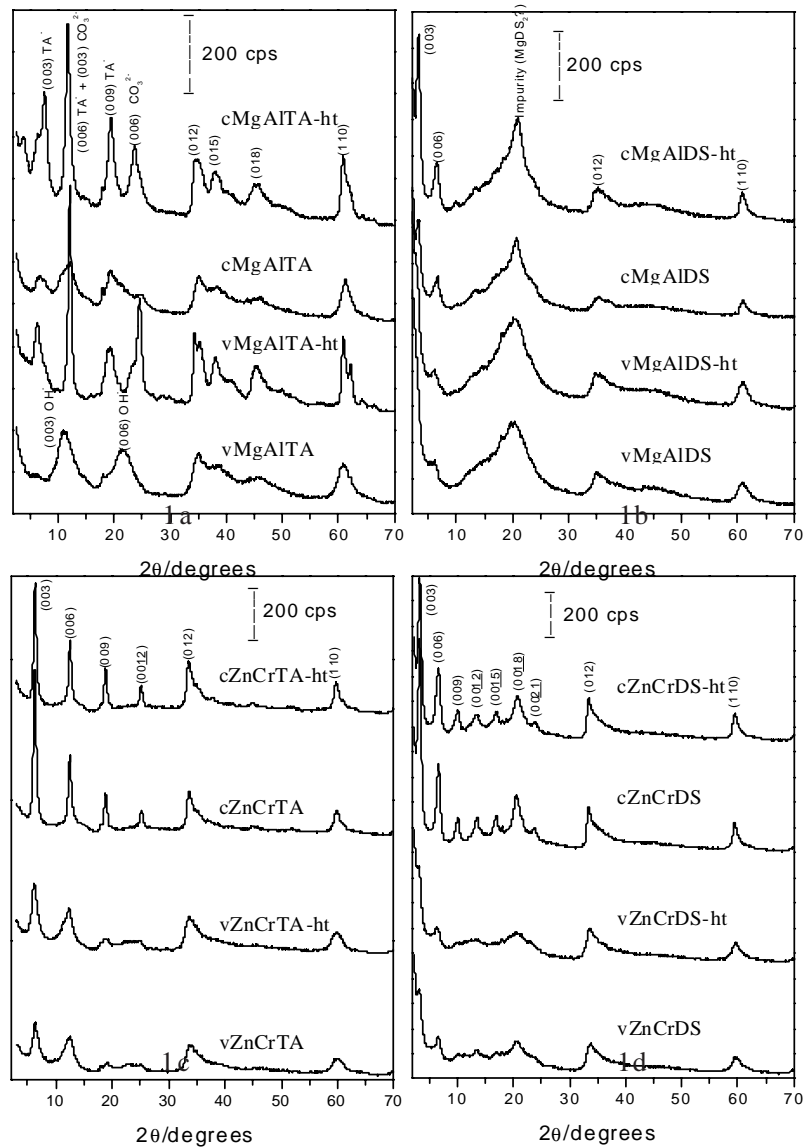

Figure 1. PXRD patterns for the following systems: a)MgAlTA; b) MgAlDS; c) ZnCrTA and d) ZnCrDS.

A general analysis of these patterns shows that the materials prepared with the $\mathrm{Zn}-\mathrm{Cr}$ cation combination presented higher crystallinity than those containing the $\mathrm{Mg}$ Al cation combination with the same interlamellar anion. Such difference in crystallinity is attributed to the higher similarity of ionic radii for the ion pair $\mathrm{Cr}$ (III)/Zn(II) (0.61/ $0.75 \AA$ ) than that for $\mathrm{Al}(\mathrm{III}) / \mathrm{Mg}$ (II) $(0.53 / 0.72 \AA)$.

It can be seen that in all of the four systems the materials obtained presented higher crystallinity when the preparation was conducted at constant $\mathrm{pH}$ than at variable $\mathrm{pH}$ values. Moreover, this crystallinity was little affected by hydrothermal treatment.

Figure 1a shows that the MgAlTA system presented a phase impurity in all cases. The vMgAlTA shows broad reflections, characteristic of LDHs intercalated with hydroxyl anions 11 . This behavior could be expected, since coprecipitation at variable $\mathrm{pH}$ facilitates the intercalation of this anion. When the material was submitted to a hydrothermal treatment (vMgAlTA-ht), this phase disappeared, and two new phases appeared. These two phases were also present in both cMgAlTA and cMgAlTA-ht, and could be attributed to: (i) the TA-containing LDH phase and (ii) a carbonate-containing LDH phase. The presence of this second phase was due to $\mathrm{CO}_{2}$ dissolution, since the hydrothermal treatment was conducted in an open system, and the medium was alkaline ( $\mathrm{pH}$ 8.5). It is also possible to observe that coprecipitation at constant $\mathrm{pH}$ led to the desired material even without treatment, and after hydrothermal treatment the material was more crystalline in relation to the TA-containing LDH, when compared to that obtained under the same treatment but at variable $\mathrm{pH}$.

Finally, the materials belonging to the MgAlDS system showed a broad reflection of about $20^{\circ}$ (2-theta) under all synthesis conditions. This broad reflection was probably due to the $\mathrm{Mg}(\mathrm{DS})_{2}$ salt, which may be formed during the synthesis and present many $\mathrm{X}$-ray diffraction peaks in that 2-theta region.

\section{Thermogravimetric analysis and differential thermal analysis}

Figure 2 presents the thermograms obtained for each prepared material, showing that each set of materials presents almost the same decomposition steps. Furthermore, the samples prepared at constant $\mathrm{pH}$ and those submitted to hydrothermal treatment presented more defined decomposition ranges. This behavior may be correlated with the higher crystallinity and phase purity of the cited materials. DTA curves (not shown) presented only endo- and isothermic processes, including those involving DS decomposition. The first decomposition step was a common feature of all of the materials prepared. This decomposition is related to water $\operatorname{loss}^{3}$, which occurs from room temperature to about $150^{\circ} \mathrm{C}$, and represents a mass loss of 5 to $10 \%$.

The TA-containing LDHs (Figures $2 \mathrm{a}$ and $2 \mathrm{c}$ ) present three decomposition steps, with the first one related to water loss, as described above. The second decomposition was related to the first step of dehydroxylation, and represented a mass loss of almost $10 \%{ }^{3}$. This decomposition occurred between 200 and $500^{\circ} \mathrm{C}$ for the materials prepared with the $\mathrm{MgAl}$ cation combination, and between 150 to $350^{\circ} \mathrm{C}$ with 


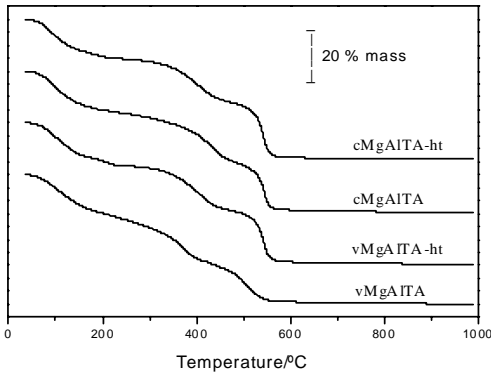

$2 \mathrm{a}$

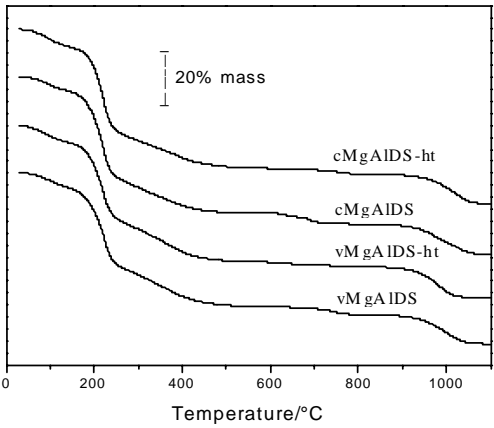

$2 \mathrm{~b}$



$2 \mathrm{c}$

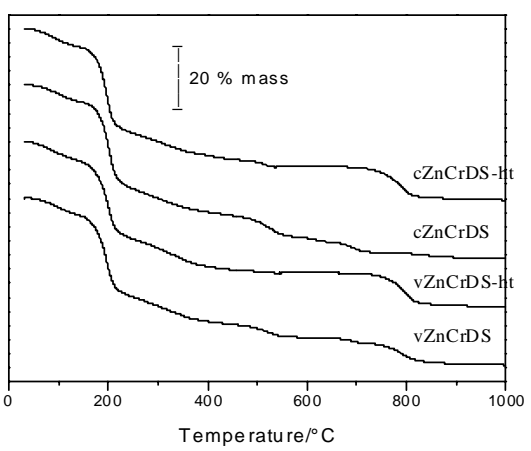

$2 \mathrm{~d}$

Figure 2. TG analysis for the following; a) MgAlTA; b) MgAlDS; c) ZnCrTA and d) ZnCrDS.

the $\mathrm{ZnCr}$ cation combination ${ }^{20}$. The last decomposition, around $20 \%$, was due to the second step of dehydroxylation and to TA decomposition ${ }^{19}$, occurring at different temperatures depending on the cation combination used, about 550 and $350^{\circ} \mathrm{C}$ for the $\mathrm{MgAl}-$ and $\mathrm{ZnCr}$-containing $\mathrm{LDHs}$, respectively. This difference may be attributed to the differ- ent TA salts formed during the heating process in each case $^{19}$. An overall view of these Figures shows that the materials obtained at variable $\mathrm{pH}$, without hydrothermal treatment, i.e. vMgAlTA and vZnCrTA, present a distinct curve shape, which was related to the amorphous material present under these conditions. However, the materials obtained at constant $\mathrm{pH}$ without further treatment showed almost the shape of those treated, indicating again that they were obtained with a considerable crystallinity without treatment.

The DS-containing materials (Figures $2 b$ and $2 d$ ) presented four decomposition steps. The first one has been already explained. The second decomposition represents a mass loss of more than $20 \%$ and is related to the first dehydroxylation step and to the DS decomposition. This decomposition step occurs at about $150-200^{\circ} \mathrm{C}$; however, TG/MS measurements (data not shown) indicated that the DS decomposition proceeded until about $600^{\circ} \mathrm{C}$. Besides the decomposition of the residual DS, the second step of dehydroxylation occurred in the same temperature range, i.e., $250-600^{\circ} \mathrm{C}$. Finally, the last decomposition can be observed at about 950 and $750^{\circ} \mathrm{C}$ for the $\mathrm{MgAl}$ and $\mathrm{ZnCr}$ cation combination respectively, and represents a $10 \%$ mass loss. This step is due to the decomposition of the residual sulfate salt originated by the DS hydrophobic chain decomposition (as observed by TG/MS measurements). The difference in the decomposition temperature is related to the distinct salts formed in each case (probably $\mathrm{MgSO}_{4}$ and $\mathrm{ZnSO}_{4}$ ). It is possible to observe that the MgAlDS thermograms are very similar. This resemblance is not observed for the $\mathrm{ZnCrDS}$ materials, for which the thermograms showed an increase in definition when the material was submitted to hydrothermal treatment. This behavior can be explained by the organization of the interlamellar domain due to hydrothermal treatment, which in turn, would not increase the crystallinity, as observed in the PXRD patterns.

\section{Size distribution and average diameter of the particles in suspension}

The curves that represent the data obtained can be seen in Figure 3. It was not possible to carry out this analysis for all of the materials due to suspension instability.

The average particle diameter varied without a correlation with material precipitation conditions or hydrothermal treatment, with values ranging from 0.5 to $0.9 \mu \mathrm{m}$. However, a correlation that can be made between particle size distribution in a suspension and type of coprecipitation used (constant or variable $\mathrm{pH}$ ) is that the distribution was less affected by the hydrothermal treatment for those materials precipitated at constant $\mathrm{pH}$, as indicated by the superimposition of the respective curves. 


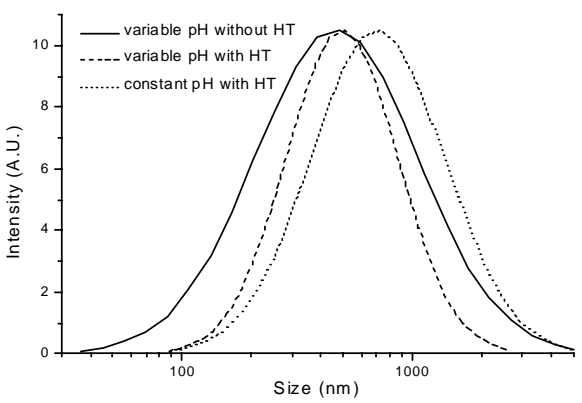

$3 \mathrm{a}$

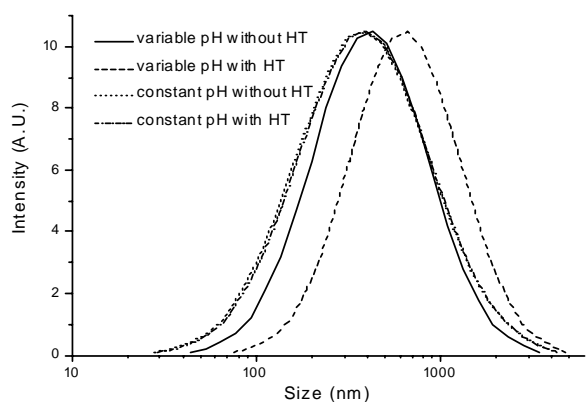

$3 b$

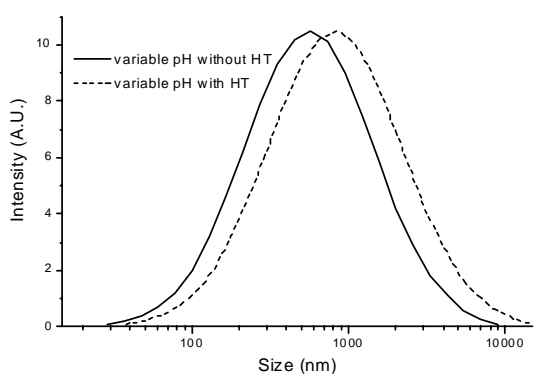

$3 \mathrm{c}$

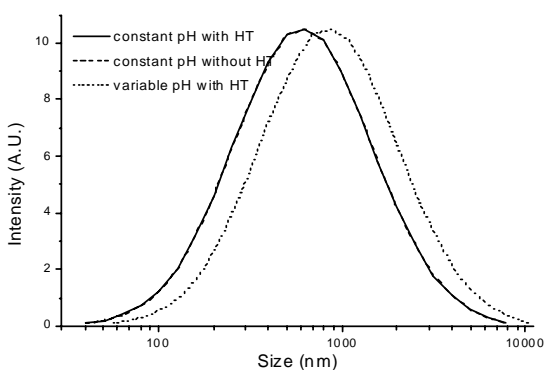

$3 \mathrm{~d}$

Figure 3. Particle size distribution of the material in suspension, related to the following systems: a) MgAlTA; b) MgAlDS; c) ZnCrTA, d) $\mathrm{ZnCrDS}$. For cases (b) and (d), two curves related to the material prepared at constant $\mathrm{pH}$ are superimposed.

\section{Specific surface area and average pore diameter}

Specific surface area and average pore diameter were determined for the $\mathrm{ZnCrTA}$ system. The results are summarized in Table 2. As one can see, materials prepared at constant $\mathrm{pH}$ presented higher specific surface areas and average pore diameter than those obtained at variable $\mathrm{pH}$ values. In the first case the values were less dependent on hydrothermal treatment, a behavior consistent with the other analyses. PXRD, TG/DTA and light scattering showed that the original characteristics of the materials prepared at constant $\mathrm{pH}$ were practically unchanged after hydrothermal treatment, showing that this condition of coprecipitation leads to better ordered materials, less dependent on further treatments such as the hydrothermal one.

Table 2. Specific Surface Area (SSA) and Average Pore Diameter (APD).

\begin{tabular}{ccc}
\hline Material & S.S.A. $\left(\mathrm{m}^{2} \mathrm{~g}^{-1}\right)$ & A.P.D. $(\AA)$ \\
\hline cZnCrTA & 39 & 250 \\
cZnCrTA-ht & 42 & 245 \\
vZnCrTA & 25 & 182 \\
vZnCrTA-ht & 5 & 156 \\
\hline
\end{tabular}

The abrupt difference in the SSA and APD values shown by the materials obtained at variable $\mathrm{pH}$ with and without hydrothermal treatment is characteristic of the organization of amorphous material by the hydrothermal treatment. As can be seen in the PXRD and TG/DTA analyses, the ZnCrTA materials presented a considerable difference in their characteristics when submitted to the hydrothermal treatment. The average diameter of the particles also increased by a factor of about $45 \%$ when they were hydrothermally treated, which is also directly related to the SSA and APD results.

\section{Scanning electron microscopy}

Representative SEM micrographs of the MgAlTA and $\mathrm{ZnCrDS}$ system materials are shown in Figure 4. The micrographs concerning the other materials (not shown) indicate that the materials obtained at constant $\mathrm{pH}$ show particles homogeneously aggregated, which means that the constituent particles are smaller. This feature was especially remarkable for the systems containing the TA anion, as can be seen in Figures $4 \mathrm{a}$ and $4 \mathrm{~b}$. Similar behavior may be found comparing Figures $4 \mathrm{c}$ and $4 d$, but in this case the particles present a plate-like morphology. The Figure also shows that the suspensions spread out, fully covering the sample holder. In these cases the surface-covering capability of the deposited suspension was much higher for the materials obtained at constant $\mathrm{pH}$.

\section{General Considerations}

The results obtained showed the advantages of using a constant $\mathrm{pH}$ in the coprecipitation method. To illustrate this aspect, Figure 5 shows the $\mathrm{pH}$ values during the precipitation of DS-containing LDHs as a function of the volume of 


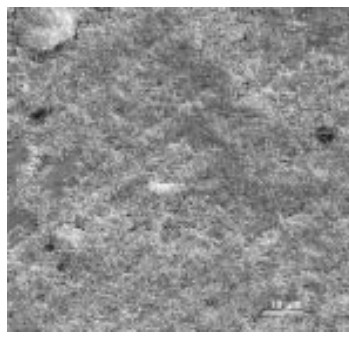

$4 \mathrm{a}$
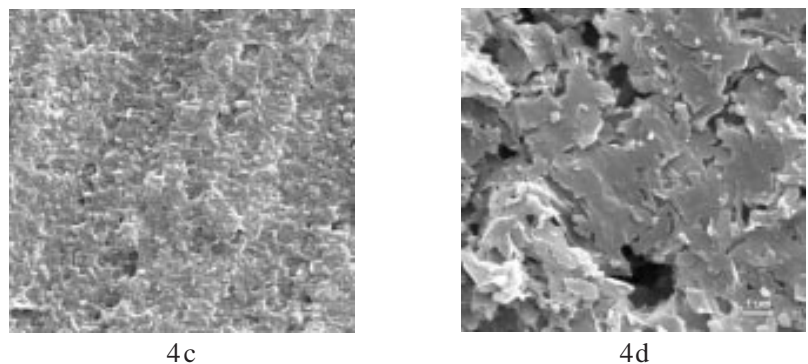

Figure 4. SEM micrographs of : a) cMgAlTA; b) vMgAlTA; c) cZnCrDS and d) vZnCrDS

the cation solution added to the reaction flask. As one can see, $\mathrm{LDH}$ formation passes through $\mathrm{pH}$ values ranging from to 13.4 to 8.3 and from 13.4 to 6.5 for the $\mathrm{MgAl}$ and $\mathrm{ZnCr}$ combinations, respectively. This should lead to more heterogeneous material, since the material precipitated at the beginning of the addition will probably differ from the one precipitated at the end. Actually, it has been previously reported that the $\mathrm{pH}$ is a determinant factor in the formation of $\mathrm{LDH}$, with a marked influence on the properties of the material obtained ${ }^{12}$. Among these properties, crystallinity is the one most affected by $\mathrm{pH}$. Phase purity can also be cited, since at the beginning of the addition (at high $\mathrm{pH}$ values), hydroxyl groups have a high tendency to be intercalated ${ }^{13}$.

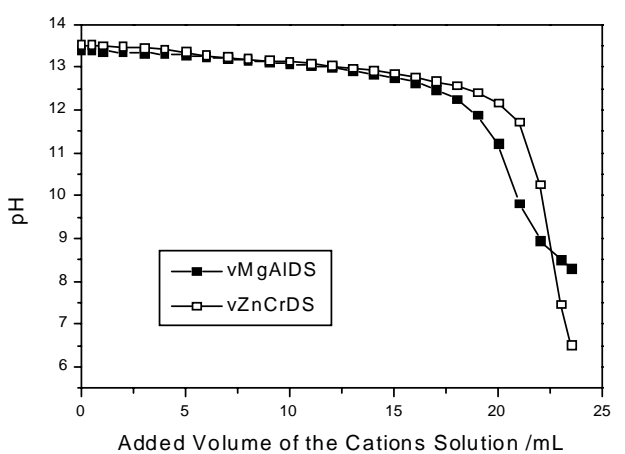

Figure 5. pH variation observed in the coprecipitation of DScontaining LDHs during the addition of the cation solution

In this way, it is possible to determine the best $\mathrm{pH}$ range for the formation of a predetermined cation combination $\mathrm{LDH}$. This will also allow to set a $\mathrm{pH}$ value that can be fitted to the anion requirements 12 .

\section{Conclusion}

On the basis of the present data, we may conclude that the coprecipitation method at constant $\mathrm{pH}$ yields materials with more interesting properties with respect to several applications for which controlled particle size and uniformity are required. In general, the crystallinity is higher for materials prepared at constant $\mathrm{pH}$, especially for the $\mathrm{Zn}$ (II)$\mathrm{Cr}$ (III) cation combination.

The choice of the conditions for the coprecipitation method will depend on the desired specific features of the materials, which can vary from one system to an other. However, the coprecipitation method with constant $\mathrm{pH}$ has been used by most investigators because of the high crystallinity, phase purity and homogeneity of the materials obtained, as observed in this work. Another advantage of this method presented here concerns the textural properties of the materials.

Finally, the advantages shown by the materials obtained by coprecipitation at constant $\mathrm{pH}$ are less influenced by the hydrothermal treatment, indicating that they present almost a stable condition that releases the hydrothermal treatment. The hydrothermal treatment is the most energetic and, in general, the longest step in LDH synthesis. Therefore, as the use of constant $\mathrm{pH}$ may avoid this step, the use of this method seems to be the best way to produce LDHs, not only due to the costs involved, but also due to the better characteristics obtained.

\section{Acknowledgments}

The authors thank the Brazilian agencies Fundação de Amparo à Pesquisa do Estado de São Paulo (FAPESP \# 95/ 5752-0, 95/3735-1, 96/6030-1 and 96/12373-9), Conselho Nacional de Desenvolvimento Científico e Tecnológico Programa de Apoio ao Desenvolvimento Científico e Tecnológico (PCNPq/PADCT) and Fundação Coordenação de Aperfeiçoamento de Pessoal de Nível Superior (CAPES) for financial support. The authors also thank Dr. C. V. Santilli for the BET isotherm measurements, and Rhodiaco Indústrias Químicas Ltda. for the donation of terephthalic acid.

\section{References}

1. Nakatsuka, T.; Kawasaki, H.; Yamashita, S.; Kohjiya, S. Bull. Chem. Soc. Jpn. 1979, 52, 2449.

2. Kohjiya, S; Sato, T; Nakayama, T.; Yamashita, S. Makromol. Chem. Rapid Commun. 1981, 2, 231.

3. Reichle, W. T. J. Catal.1985, 94, 547.

4. Suzuki, E.; Ono, Y. Bull. Chem. Soc. Jpn.1988, 61, 1008.

5. Schaper, H.; Berg-Slot, J. J.; Stork, W. H. J. Appl. Catal. 1989, 54, 79. 
6. Barloy, L.; Lallier, J. P.; Battioni, P.; Mansuy, D.; Piffard, Y.; Tournoux, M.; Valim, J. B.; Jones, W. New J. Chem. 1992, 16, 71 .

7. Pavan, P. C. ; Gomes, G. A.; Valim, J. B. Micropor. Mesopor. Mater. 1998, 21, 659.

8. Miyata, S.; Kumura, T. Chem. Lett. 1973, 843.

9. Meyn, M.; Beneke, K.; Lagaly, G. Inorg. Chem. 1990, 29, 5201.

10. Boehm, H. P.; Steinle, J.; Vieweger, C. Angew. Chem. Int. Ed. Engl.1977, 16, 265.

11. Reichle, W. T. Solid State Ionics 1986, 22, 135.

12. de Roy, A.; Forano, C.; El Malki, K.; Besse, J. P. In Synthesis of Microporous Materials, Occelli, M. L.; Robson, H.E.; Ed. Van Nostrand Reinhold, New York, 1992, vol. II, p. 108.
13. Lal, M.; Howe, A. T. J. Solid State Chem. 1981, 39, 368.

14. Indira, L.; Dixit, M.; Kamath, P. V. J. Power Sources 1994, 52, 93.

15. Indira, L; Kamath, P. V. J. Mater. Chem. 1994, 4, 1487.

16. Lopez, T.; Bosch, P.; Ramos, E.; Gomez, R.; Novaro, O.; Acosta, D.; Figueras, F. Langmuir 1996, 12, 189.

17. Shirahama, K; Kashiwabara, T. J. Colloid Interface Sci. 1971, 36, 65.

18. Morpurgo, S.; Lojacono, M.; Porta, P. J. Mater. Chem. 1994, 4, 197.

19. Drezdzon, M. A. Inorg. Chem. 1988, 27, 4628.

20. Fuda, K.; Suda, K. Matsunaga, T. Chem. Lett. 1993, 1479.

Received: August 17, 1998

FAPESP helped in meeting the publication costs of this article. 